\title{
PLANT DESIGN FOR EFFICIENCY USING AUTOCAD AND FACTORYFLOW
}

\author{
David P. Sly \\ CIMTECHNOLOGIES CORPORATION \\ 2501 North Loop Drive, Suite 700 \\ Iowa State University Research Park \\ Ames, Iowa 50010, U.S.A.
}

\begin{abstract}
Designing industrial facilities in AutoCAD is very different from designing the office and laboratory environments typically discussed at AEC-oriented shows and seminars. In factories the cost of moving equipment and automated material handling systems is significant, making their initial placement critical. In addition, factories are designed for the optimal flow of materials, which requires a significant quantitative review and can be very time consuming and difficult to present. This paper will discuss the systematic approach to the design of industrial facilities and how this approach can be greatly simplified with the use of such tools as AutoCAD with FactoryFLOW
\end{abstract}

\section{INTRODUCTION}

FactoryFLOW is a detailed material flow analysis tool that works inside of AutoCAD for the purpose of analyzing, reporting and diagramming material flow within factory layouts. While often used for the quantitative and graphical evaluation of multiple layouts, FactoryFLOW with a systematic design approach can lead the user to the most optimal design feasible given the many real-world constraints evident in existing facilities. By working right inside of AutoCAD, FactoryFLOW can take existing AutoCAD layouts and combine part/product routings from spreadsheets and MRP systems. FactoryFLOW then automatically generates detailed, variable width and color, material flow diagrams on product-named layers inside of AutoCAD. Once the diagrams have been generated and the actual travel distances computed, FactoryFLOW can create detailed reports on material flow cost, distance, frequency and time, allowing the user to evaluate the effectiveness and efficiency of the layout and material handling system design

\section{THE SYSTEMATIC FACTORY LAYOUT APPROACH}

You cannot adopt Just In Time, Focused Factories, Manufacturing Cells, Group Technology, or Continuous Flow Manufacturing without first designing a production layout that supports that manufacturing methodology. Too often, factory layouts are created independent of a clear focus of the operating strategy to be employed within the system. Under any circumstances, material flow will be the key driver of how each of these production systems will be designed, and material flow should then be used as the key measure of their effectiveness.

The systematic factory layout approach defined by Muther (1973) takes a phased approach to the layout design starting from general to specific and involving both quantitative flow and qualitative relationship analyses based on products, quantities, routings, support services and timing. The quantitative approach involves a detailed analysis of material flows based on several layout configurations and is the heart of an industrial layout analysis. The qualitative approach is used to ensure that all criteria with respect to noise, dirt, contamination, air quality, fire hazards, supervision, safety, and so on are being met. Small studies can be done entirely qualitatively by taking material flow and classifying it into different relationship categories while large studies would employ both quantitative and qualitative studies simultaneously.

\section{BASIC MATERIAL FLOW ANALYSIS TECHNIQUES}

Material flow diagrams illustrate material moves FactoryFLOW can generate a variety of diagrams from the same set of data, allowing the anlayst to focus on different aspects of flow. The key diagram from which all others are computed is the product flow diagram (Figure 1). This diagram shows different products/ 
subassemblies/materials/processes in different colors and with line thickness according to either number of trips or cost. This diagram can be presented with actual paths for better numerical evaluation and aisle congestion analysis, or Euclidean paths for better visual evaluation of workcenter interrelationships. One key of the product flow diagram is that it is intelligent: a user can click on a line to find out what it represents (Figure 2). In addition, if users rearrange the equipment in AutoCAD they need only select CALC again and FactoryFLOW can find all of the new locations, regenerate the flow diagram and recompute the costs, distances, intensities and time. It is this iterative approach with instant graphical and quantitative feedback that makes quantitative layout evaluation feasible.

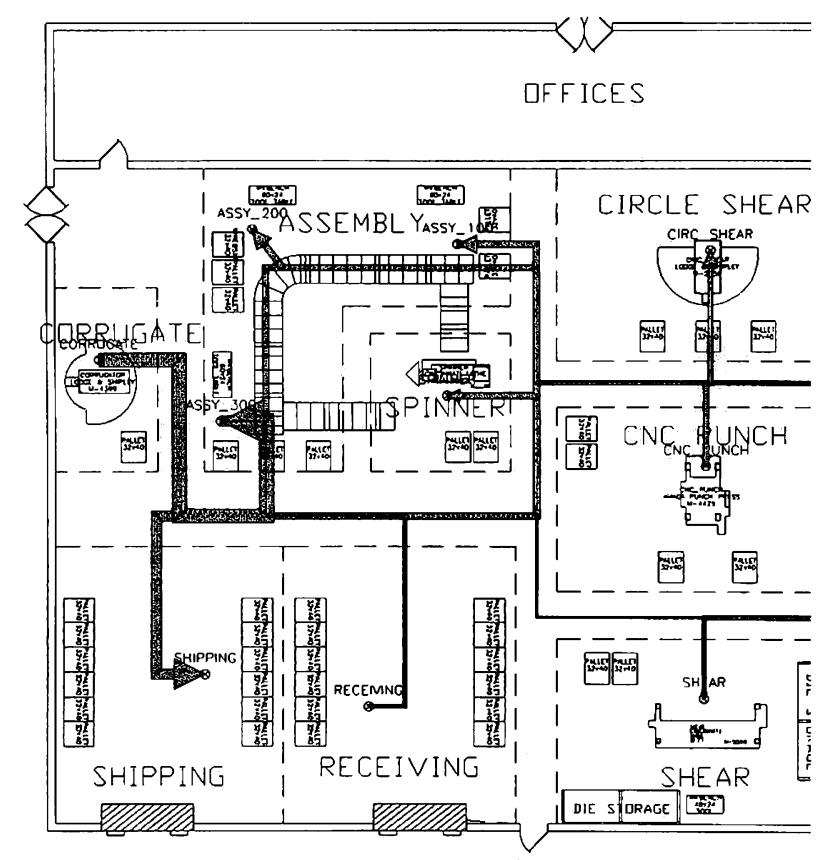

Figure 1: Product Flow Diagram-Actual Paths

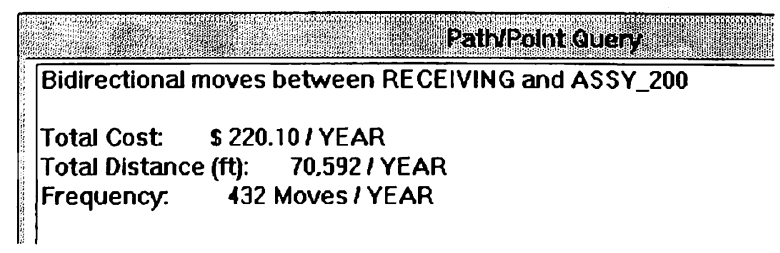

Figure 2: Path Query

The flow diagram filtering option (Figure 3) is another advantage of intelligent flow paths. Users can select for viewing just the flows that match a specific database filter. Common filters are flows in to and/or out of a location, flows for a specific product grouping, or flows that use specific material handling equipment.

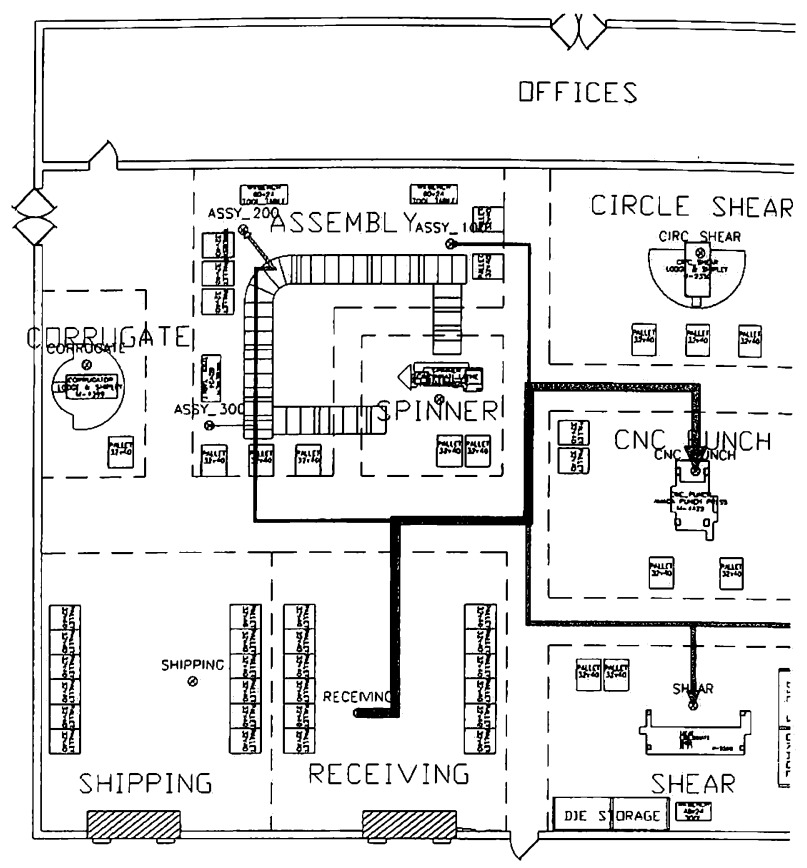

Figure 3: Diagram Filtering-Flows From Receiving

The composite flow diagram (Figure 4) is created from the product flow diagram (Figure 1) and is used to determine the total material flow between two locations as well as the amount of flow in each direction if backtracking exists. Composite flow diagrams sum up all of the flows from the individual product routings.

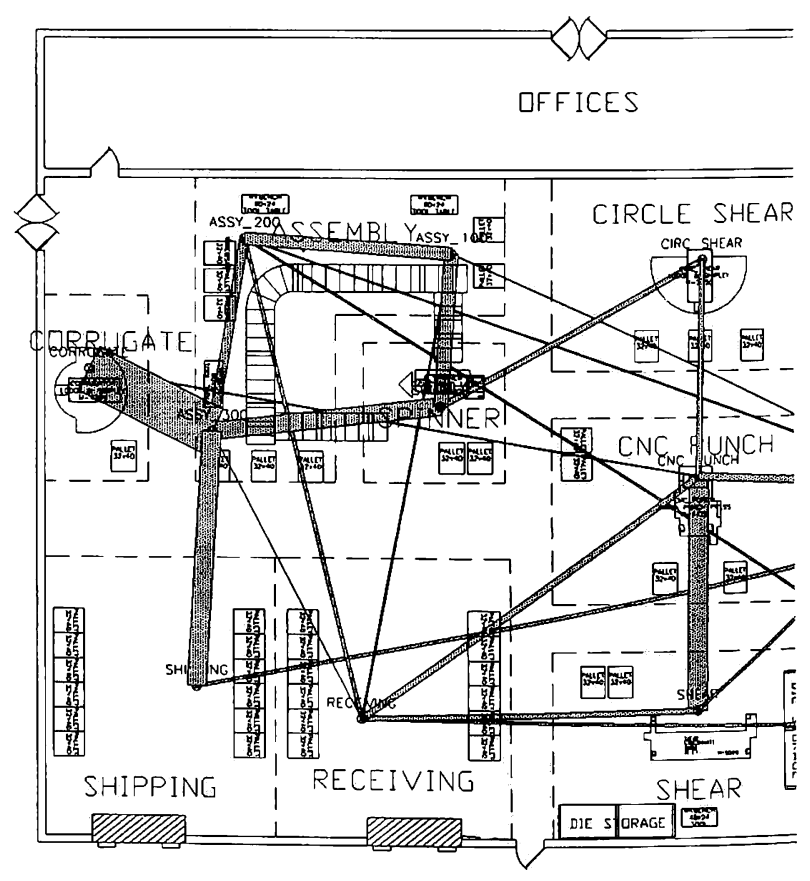

Figure 4: Composite Directional/Bi-directional Flow Diagram 
Diagrams are critical for the evaluation and communication of material flow and layouts. However, the diagrams typically generate many questions that need to be confirmed numerically. When FactoryFLOW creates the diagrams in AutoCAD, it also summarizes the information in detailed reports as shown in Figures 5 and 6.

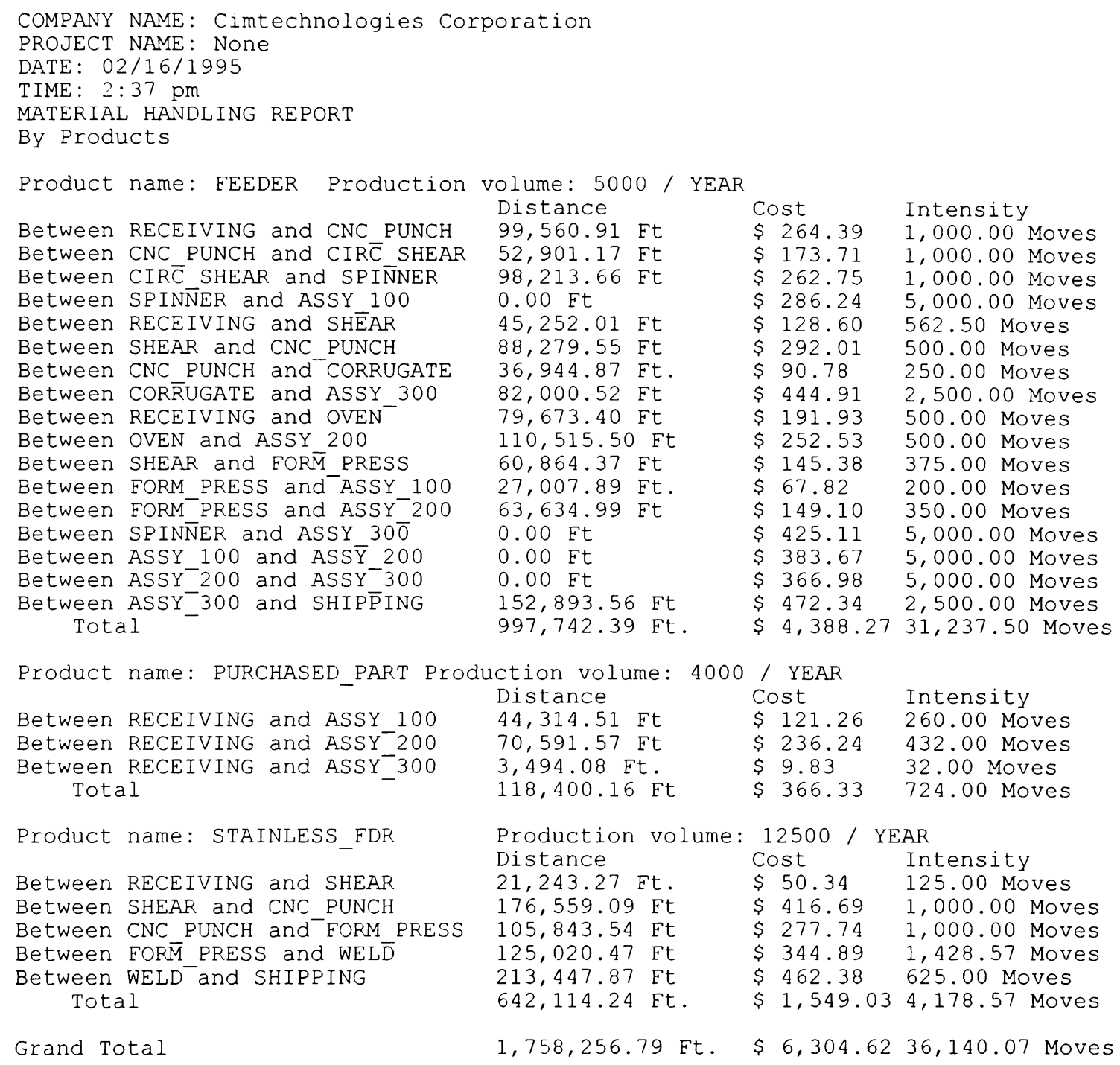

Note: Moves with zero distance are accomplished using conveyors, where actual distance travelled has little to no bearing on variable material handling costs. Costs shown for such moves are related to fixed costs apportioned according to percentage of use.

Figure 5: Simple Flow Results, Arranged by Products 


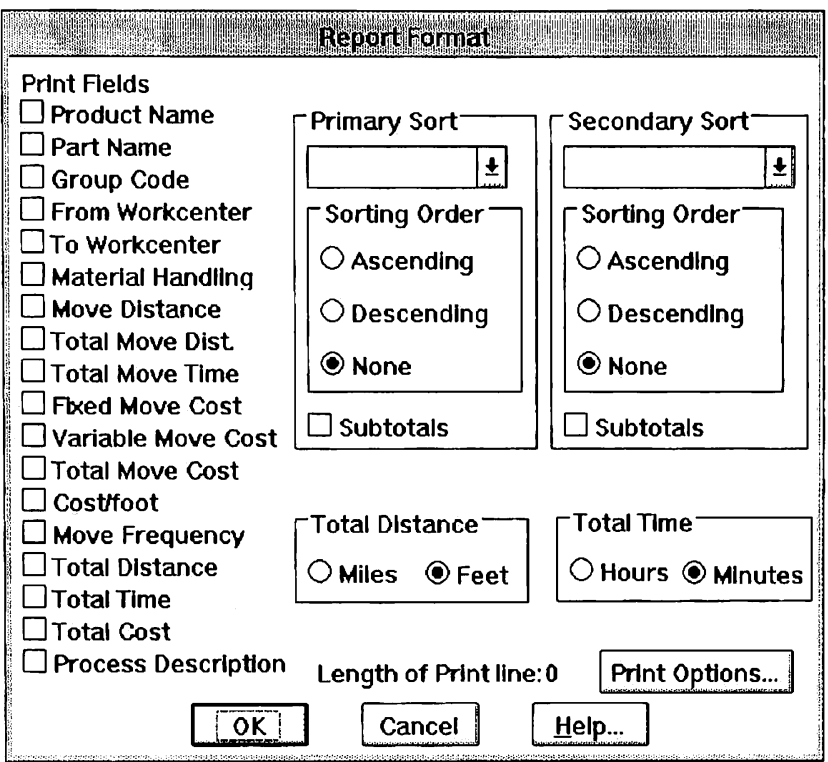

Figure 6: Advanced Report Format Selection Screen

Sometimes flow diagrams can contain too much information. The following three charts allow users to look at the same problem from different angles. The product quantity $(\mathrm{PQ})$ chart (Figure 7) is designed for job shops and other component manufacturers to use to identify products whose layout design would be good for "product focused," "cell focused," or "process focused" configurations. The distance intensity (DI) chart (Figure 8) is used to show how well both the layout and the material handling system have been designed. With DI charts, an excellent design is one in which all points are against the axes. Any points in the middle of the chart indicate that either the units/trip or the layout are inefficient. Finally the from-to chart (Figure 9) is used to show the intensity or volume of flow in to a location, out of a location or between two specific locations. This chart is also good for color coding major flow volumes (intensities) so that the key problem areas are easily identified.

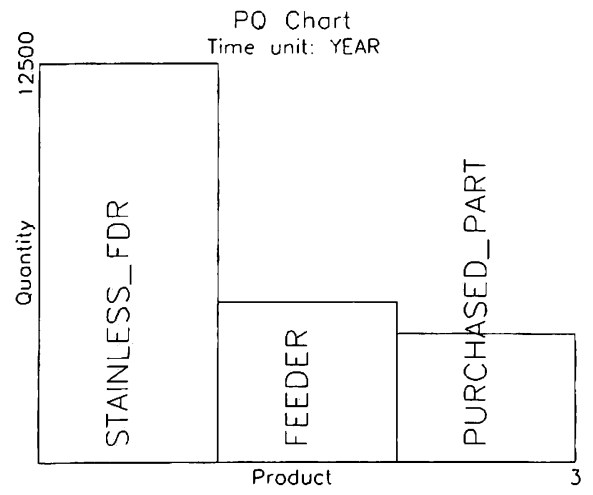

Figure 7: Product Quantity Chart

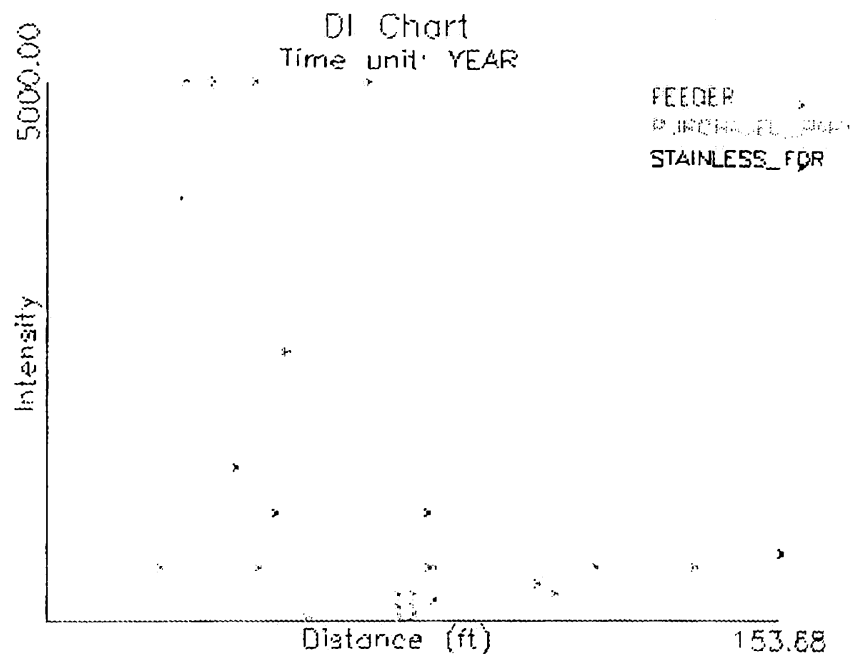

Figure 8: Distance Intensity Chart

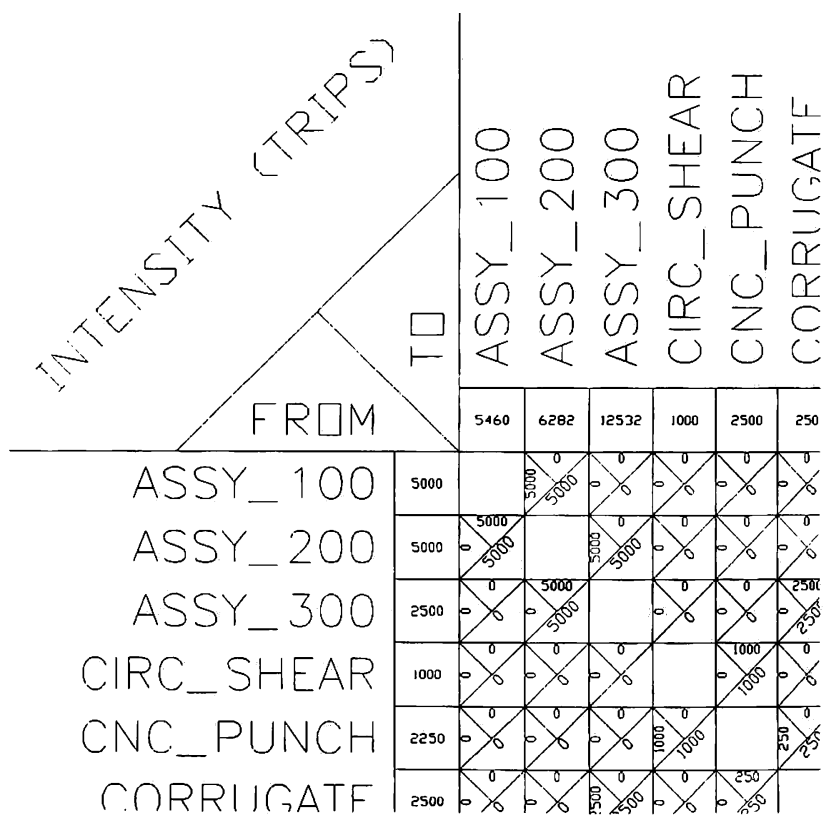

Figure 9: From-To Chart

\section{ADVANCED MATERIAL FLOW ANALYSIS TECHNIQUES}

Once the basic flow analysis techniques are implemented, users may need to evaluate detailed cellular and clustered flows. FactoryFLOW's cluster analysis capability (Figure 10) allows users to make a cluster out of a set of exclusive workcenter points. Instead of diagramming from point to point among the two cluster sets, FactoryFLOW only diagrams the cumulative flow between clusters. Reports can then be created which quantify the flow between and within 
these geographic clusters. Cluster analysis is excellent when looking at interdepartmental, intercellular, or interbuilding flows. In semiconductor plant applications, clusters allow for the quick analysis of interbay flows.

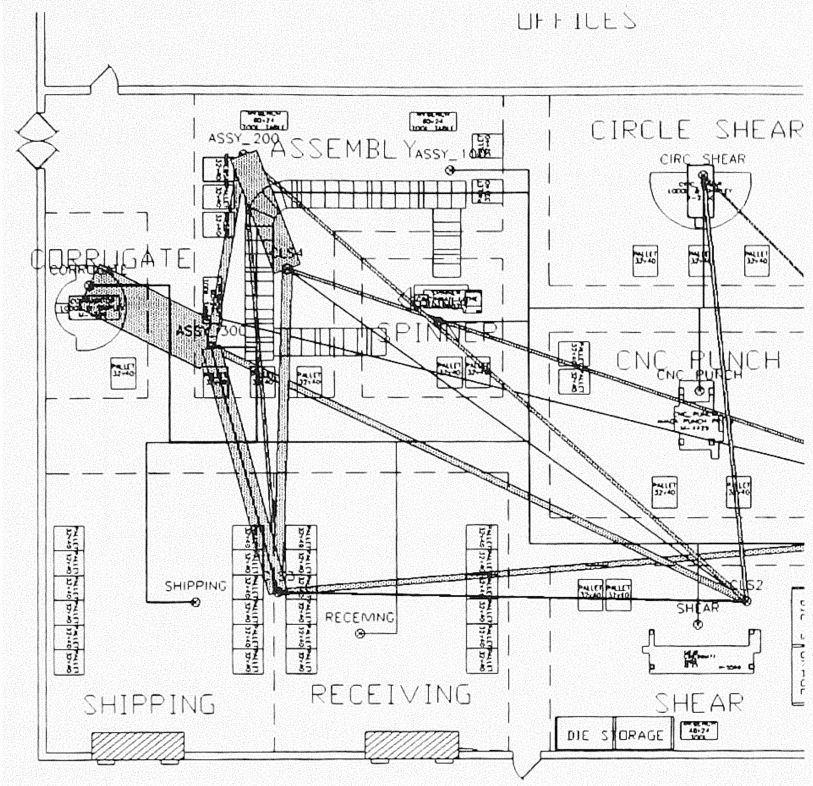

Figure 10: Cluster Analysis

Determining how best to route flow becomes an intricate problem when more than one workcenter could perform a particular operation, and when individual workcenters perform multiple operations. The problem of optimizing flow for multiple workcenters occurs in such varying real-world examples as with an automotive plant's loading docks or a semiconductor fabricator's lithographic machines. Certain material coming to an automotive plant could conceivably be accommodated at any one of multiple docks, and can be transported to any one of multiple workcenters. Wafers in a semiconductor fabrication plant could travel to any one of multiple servers several times in the course of a multiple reentrant flow process.

Workcenter grouping examines flow from this perspective: given workcenter locations and capacities, what routing will result in the shortest total travel distance? This approach allows users to specify a group name for a location in a product/part routing and then let FactoryFLOW select the best piece of equipment in the group to use in that specific part of the routing in order to reduce factorywide material flow while preserving fixed equipment capacities.

FactoryFLOW can also perform static utilization studies on the equipment (Figures 11 and 12) in order to determine roughly how many pieces of equipment would be needed for each cell or focused factory. This information is critical in the cell and factory layout design phases, as considerable space may need to be reserved for existing or future growth processes. This static analysis capability allows FactoryFLOW to perform grouping studies and feed data to more dynamic analyses later in the design stage.

\begin{tabular}{|c|c|c|c|c|}
\hline \multicolumn{5}{|c|}{ WorkCenter Utilization } \\
\hline \multirow{3}{*}{$\begin{array}{l}\text { Prod. Flle: } \\
\text { Part. File: } \\
\text { Util. Flle: }\end{array}$} & \multicolumn{4}{|c|}{ CIUSERIHOGFEEDR } \\
\hline & \multicolumn{4}{|c|}{ CIUSERIHOGFEEDR } \\
\hline & \multicolumn{4}{|c|}{ C:IUSERIHOGFEEDR } \\
\hline $\begin{array}{l}\text { ACTIVITY } \\
\text { AREA }\end{array}$ & $\begin{array}{l}\text { OF } \\
\text { SERV }\end{array}$ & $\begin{array}{l}\text { AVAIL MIN } \\
\text { IVEAR }\end{array}$ & $\begin{array}{l}\text { BUSY MIN } \\
\text { NEAR }\end{array}$ & $\begin{array}{l}\text { UTIL } \\
(\%)\end{array}$ \\
\hline CNC_PUNCH & 1.000 & 115200 & 87244 & 75.733 \\
\hline CIRC_SHEAR & 1.000 & 115200 & 18877 & 16.386 \\
\hline SPINNER & 1.000 & 115200 & 33561 & 29.133 \\
\hline SHEAR & 1.000 & 115200 & 83573 & 72.546 \\
\hline CORRUGATE & 1.000 & 115200 & 34183 & 29.673 \\
\hline \multirow{2}{*}{$\begin{array}{l}\text { OVEN } \\
\text { FORM_PRESS }\end{array}$} & 2.000 & 115200 & 91212 & 39.588 \\
\hline & 1.000 & 115200 & 89990 & 78.116 \\
\hline ASSY_100 & 1.000 & 115200 & 75376 & 65.431 \\
\hline ASSY_200 & 1.000 & 115200 & 85427 & 74.155 \\
\hline ASSY_300 & 1.000 & 115200 & 75376 & 65.431 \\
\hline WELD & 1.000 & 115200 & 72164 & 62.643 \\
\hline SrchRp & $K$ & Cancel & Help... & Crall \\
\hline
\end{tabular}

Figure 11: Equipment and Workstations

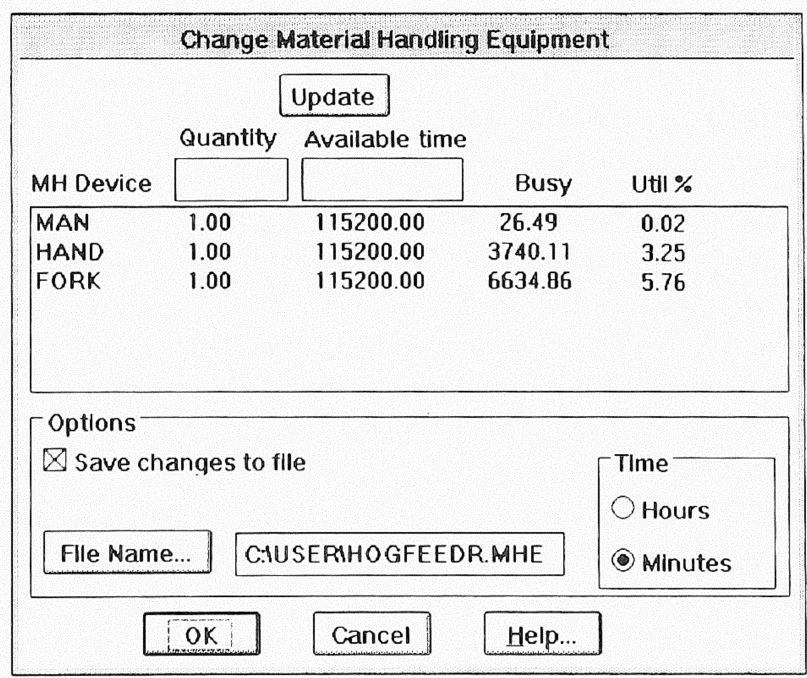

Figure 12: Material Handling Equipment

Thorough production system design incorporates study of a number of components: a facility drawing, the layout of machines and workcenters, material flow, capacity requirements, buffer sizes, scheduling considerations, flow logic, production downtime, and possibly simulation or animation for presentation and error checking. These components can be divided into static and dynamic categories (Figure 13). 


\begin{tabular}{|l|l|}
\hline $\begin{array}{l}\text { Static components of production do not vary } \\
\text { significantly over time. They can be studied as } \\
\text { though they were constant, thus greatly } \\
\text { simplifying the design problem and producing } \\
\text { effective designs in a minimal amount of time. }\end{array}$ & $\begin{array}{l}\text { - facility drawing } \\
\text { - material flow } \\
\text { - some estimates of equipment capacities }\end{array}$ \\
\hline $\begin{array}{l}\text { The dynamic components of production system } \\
\text { and manufacturing cell design analyze } \\
\text { phenomena which vary over time. Therefore, the } \\
\text { analyst must not only specify the individual } \\
\text { process times of each machine, operator and } \\
\text { transport device, but also specify how these times } \\
\text { vary with respect to time. }\end{array}$ & $\begin{array}{l}\text { - dynamic capacity requirements } \\
\text { - buffer sizes }\end{array}$ \\
\hline
\end{tabular}

Figure 13: Static vs. Dynamic Production Design Elements

Because of the increased input data and statistical analysis required, the scope of any individual component of dynamic analysis must typically be smaller than for static analyses (for example, limited to one workstation or cell versus the whole factory).

Many of the input data for dynamic analyses come from results of the static analyses. This data progression makes a phased approach essential. In order to achieve the best designs in the shortest possible time, designers must first determine the layout and material flow before undertaking any dynamic analyses.

\section{FOCUSED FACTORIES AND MANUFACTURING CELL DESIGN}

The goal of manufacturing cells and focused factories is to cluster or group together the routings/flows of material for groups of routings that have commonality according to product or process.

In focused factories product families are grouped together for the purpose of reducing overall product throughput, inventory, and thus materials management. This arrangement works particularly well in situations where setup times from one part to another at the same work station do not vary greatly, and where it is common to have many different product varieties with respect to color, size, or special options produced in a small time frame for the purpose of reducing finished goods inventory.

When designing focused factories it is important to select the product families based on this operating strategy, and then assign them the same color in FactoryFLOW. The task then is simplified to one of grouping all of the colored flows by color and working out machine assignment and location so that first the color groups are reduced and then the material flow in each color group is ideal. This task is greatly simplified in this graphical approach because it allows the users to see both the tradeoffs and relative flow intensities. In addition, this graphical approach lends itself well to productive group involvement.

In manufacturing cells common production processes are grouped together. Ideally this grouping is also done with respect to product family so that overall product throughput within the factory is reduced along with just the flow in the cell. If no product families are involved and just process and part commonality is considered, this grouping is often referred to as group technology (GT). GT can work well to reduce the throughput and inventory of a subset of the manufacturing process, especially a complicated one However, if the subset is not integrated into the product flow overall, the subset can still become a bottleneck in the facility as a whole.

When designing manufacturing cells, designers often create many different groupings and then evaluate them using the same color and intensity groupings as in focused factories. The key difference is that the cell groupings are often iterated to accomplish different factorywide or productwide throughput goals, and then these manufacturing methodologies are evaluated with respect to the efficient material flows, layouts and throughputs that they create.

\section{OTHER TOOLS AND TECHNIQUES}

While material flow is the primary design factor used for industrial facilities, space and qualitative relationships cannot be ignored. FactoryPLAN (Figure 14) was designed for the evaluation and comparative 
analysis of qualitative activity relationships. With FactoryPLAN, analysts determine the relationships between activities such as storage, equipment, support, docks, doors, and floor support using an AEIOUX ranking method. An " $A$ " relationship is the most important, a " $U$ " is Unimportant, and " $X$ " is negative. Analysts rank the relationship of each activity and then manipulate FactoryPLAN to generate the spacerelationship diagrams and score them interactively as with FLOW. A FactoryPLAN analysis is very quick and easy to do, requiring only the information available firsthand from the group of people working in the area.

Space planning (Figure 15) for factories is typically used to evaluate cost centers for cost allocation and also to determine measures of productive to unproductive space, or manufacturing to storage to aisles. Effective space planning methods are beyond the scope of this paper. However, good space planning can be critical for the planning of WIP and reduced throughput.

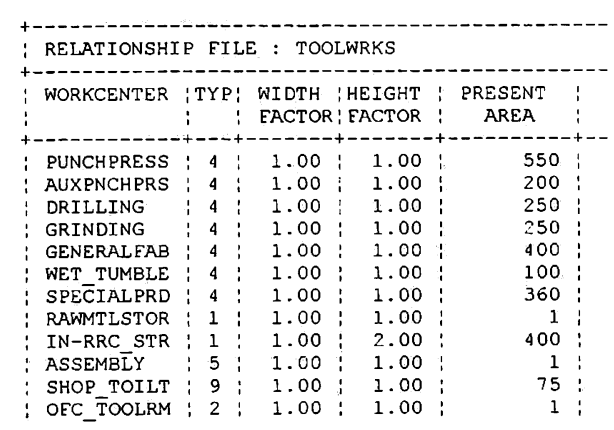

Step 1

Enter area and space data.

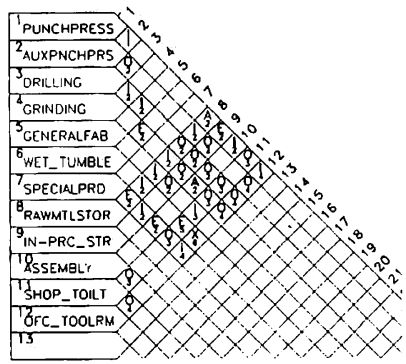

Step 2

Enter relationship data.

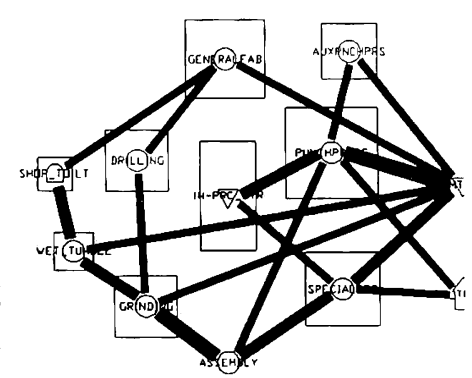

Step 3

Generate and manipulate the relationship diagram.

Figure 14: Relationship Planning
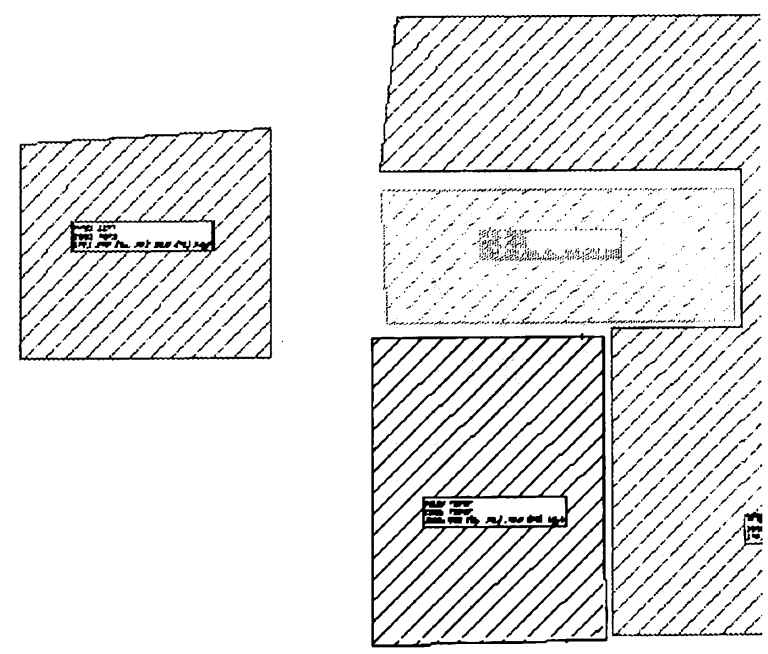

Figure 15: Space Planning

\section{CONCLUSION}

Good factory layout design is a science involving both quantitative, qualitative and strategic information. With products and production requirements changing annually, successful manufacturers will be required to develop and redevelop efficient production systems continuously. Only through the effective use of systematic design software and methodologies like AutoCAD and FactoryFLOW will manufacturers be able to remain competitive and provide the quality products that consumers expect at the profit margins that stockholders require.

\section{ACKNOWLEDGEMENTS}

The author would like to thank Emil Polashek for his editing and layout of this manuscript, as well as the many valuable employees of Cimtechnologies Corporation and Autodesk for producing such fine tools for industrial facilities design and analysis.

FactoryCAD, FactoryPLAN and FactoryFLOW are registered trademarks of Cimtechnologies Corporation. AutoCAD and AutoLISP are registered trademarks of Autodesk, Inc. 


\section{REFERENCES}

Muther, R., and J. Wheeler. 1988. Simplified systematic lai'(out planning. Kansas City, Missouri: Management and Industrial Research Publications.

Muther, R., and K. Haganas. 1987. Systematıc handling analysis. Kansas City, Missouri: Management and Industrial Research Publications.

Muther, R. 1973. Sistematic layour planning. Kansas City, Missouri: Management and Industrial Research Publications.

Sly, D., and E. Polashek. 1993. Fairtron scores big with new cabinet production layout design. Industrial Englneering, 34-36.

Sly, D. J. Labban, and V. Tamashunas. 1990. Interactive graphics offer an analysis of plant layout and material handling systems. Industrial Engineering, 86-89.

\section{AUTHOR BIOGRAPHY}

DAVID P. SLY is president and founder of Cimtechnologies Corporation and original author of the FactoryCAD, FactoryPLAN and FactoryFLOW products. Mr. Sly has been involved with industrial facilities layout and design for over ten years performing consulting and development projects for John Deere, Ford, GM, SEMATECH, AT\&T, and many other fortune 100 manufacturers worldwide. David received his bachelors and masters degrees in Industrial Engineering as well as his MBA from Iowa State University. He is a registered professional engineer in the state of Iowa, and is a member of the Society of Manufacturing Engineers, Institute of Industrial Engineers, and the Society for Computer Simulation. 